\title{
The morality of assisted reproduction and genetic manipulation
}

\author{
A moralidade da reprodução assistida \\ e da manipulação genética
}

Maurizio Mori 1,2

1 Dipartimento di Filosofia, Università di Pisa.

Piazza Torricelli 3/a 56126, Pisa, Italia. maumori@digicolor.net 2 Bioetica.

Rivista Interdisciplinare

Zadig Editore.

Via Lanino 5, 20144

Milano, Italia.

zadig@micronet.it
Abstract The author analyzes the pros and cons of various forms of assisted reproduction, including the use of so-called 'genetic manipulation'. He shows how in ethics the only arguments with any chance of reaching a consensus (or at least an agreement) are those of the rational type, based on universally acceptable ethical principles or corroborated by empirical facts and real life experience (as the starting point for identifying problems requiring analysis). After an analysis in which he identifies the incoherence and inconsistency of arguments against assisted reproduction, the author defends the right of human beings to deci de autonomousl y about the most healthy forms of procreation, including those involving genetic manipulation. His starting point is the moral principle by which it is morally preferable to intervene in natural processes (as opposed to not intervening) whenever this implies preventing and reducing disease and suffering. Key words Reproduction; Medical Genetics; Bioethics

Resumo $\mathrm{O}$ autor se propõe a analisar os argumentos pró e contra as várias formas de reprodução assistida, inclusive aquela dependente da assi m chamada mani pulação genética. Mostra como os únicos argumentos com chance de chegar ao consenso, ou, pelo menos, a um acordo, sejam os argumentos racionais, embasados em princípi os éticos (universalmente acei táveis), ou corroborados por fatos empíricos e experiências de vida (como ponto de partida para identificar os problemas que requerem análise). Após uma parte desconstrutiva, na qual aponta a incoerência e a inconsi stência dos argumentos contrários, o autor defende o direi to dos humanos em decidir autonomamente acerca das formas mais saudáveis de procri ação, inclusi ve aquel as que envol vem mani pulações genéticas. Para tanto, baseia-se no princípio moral segundo o qual é moral mente preferível interferir nos processos naturais que não intervir quando isso i mplica prevenir e reduzir doenças e sofrimento.

Palavras-chave Reprodução; Genética Médica; Bi oética 
Preliminary remarks

By 'morality' I mean a set of deeply internalized rules and convictions or strong feelings that an individual believes to be rationally justified. While taste and esthetic preferences need no rational justification and the presence of a feeling is self-justifying, moral attitudes are supposed to be supported by universally accepted reasons. Such reasons are either empirical facts relevant to the issue or ethical principles accepted by everyone or at least by society as a whole.

The emotive aspect implicit in morality explains why moral controversies are often so hotly debated and why they usually involve radical disagreements, making peaceful dialogue on the issue impossible. However, I think that no matter how strong feelings may be, they can never be considered 'moral' unless there are good reasons to justify them. To be morally respectable, an attitude must be tested by rational scrutiny, and we should be able to articulate valid reasons on its behalf. This brings us to a crucial divide on different approaches to morality. According to some authors, certain moral feelings are so deep that they are selfjustifying, and there is no way to make the reasons for them clear. In one sense, such deep feelings resist rational analysis, and any attempt in this direction is misleading. Leon Kass (1997) holds such a view when he writes: "Revulsion is not an argument, and some of yesterday's repugnances are today calmly accepted though, one must add, not al ways for the better. In crucial cases, however, repugnance is the emotional expression of deep wisdom, beyond reason's power fully to articulate it" (Kass, 1997: 20). Kass goes on to say, "The repugnanceat human cloning belongs in this category. We are re pelled by the prospect of cloning human beings not because of the strangeness or novelty of the undertaking, but becauseweintuit and feel, immediately and without argument, the violation of things that we rightfully hold dear. Repugnance, here as el sewhere, revolts agai nst the excesses of human willfulness, warning us not to transgress what is unspeakably profound" (Kass, 1997:20, emphasis added).

I realize that having reached such a point, it is difficult to obtain any kind of agreement, and possibly different views are incommensurable (to use a fashionable word). In any case, I reject the alleged intrinsic 'wisdom of repugnance', because we have no criteria to distinguish between some cases in which deep feelings are simply unjustified gut reactions to be overcome and other cases which are not. So, my view is that in order to hold a moral position we must be able to fully articulate good reasons for our favorable or aversive attitudes. Otherwise, we may keep such feelings as private preferences typical of our own personal way of life, but we cannot claim any stronger validity for them.

These preliminary remarks seemed necessary because there are quite different attitudes and feelings towards assisted reproduction. Some people think it is a horrible interference in the natural procreative process and a violation of something which is 'unspeakably profound' (to use Kass's words) to be left to random selection. Others hold that it is a significant advance fostering control over reproduction and therefore increasing parental freedom. Given such a contrast, we must find reasons to justify a possible limitation to (or even prohibition of) assisted reproductive techniques. If we are unable to identify such reasons, we must realize that no moral prohibition of assisted reproduction can be made.

Against the principle of inseparability of sexuality and reproduction

What reasons might support a moral opposition to assisted reproduction? The first and most general one is the principle requiring the inseparability of the unitive and procreative meanings implicit in human sexual intercourse. This is the main underlying argument in the Roman Catholic position. As we read in the Instruction Donum Vitae: “The Church's teaching on marriage and human procreation affirms the inseparable connection, willed by God and unable to be broken by man on his own initiative, between the two meanings of the conjugal act: the unitive meaning and the procreative meaning. Indeed, by its intimate structure, the conjugal act, while most closely uniting husband and wife, capacitates them for the generation of new lives, according to laws inscribed in the very being of man and of woman' (Pope Paul VI, Encyclical Letter Humanae Vitae, 12). This principle, which is based upon the nature of marriage and theintimateconnection of the goods of marriage, has well-known consequences on thelevel of responsiblefatherhood and motherhood. 'By safeguarding both these essential aspects, the unitive and the procreative, the conjugal act preserves in its fullness the sense of true mutual love and its ordination towards man's exalted vocation to parenthood' (HumanaeVitae, 12).

The same doctrine concerning the link be tween the meanings of the conjugal act and be 
tween the goods of marriage throws light on the moral problem of homologous artificial fertilization, since 'it is never permitted to separate these different aspects to such a degree as positively to exclude either the procreative intention or the conjugal relation' (PopePius XII, Discourse, May 19, 1956). Contraception deliberately deprives the conjugal act of its openness to procreation and in this way brings about a voluntary dissociation of the ends of marriage. Homologous artificial fertilization, in seeking a procreation which is not the fruit of a specific act of conjugal union, objectivel y effects an analogous separation between the goods and the meanings of marriage" (Congregation for the Doctrine of the Faith, 1987:26-27).

I have included this long quote because it makes clear both the real core of the Roman Catholic position and the principle on which it depends. Too often the discussion on the issue is misleading, pointing to other aspects of practice, while the passage quoted above clearly identifies the principle involved in the moral judgment, i.e. the so-called 'principle of inseparability of the unitive and procreative meanings of sexual act'. This principle is practically equivalent to a general prohibition of any artificial intervention in the natural process and wards off any sort of assisted reproduction. To be precise, this position allows for so-called artificial reproduction impropriedictae, i.e. an intervention aimed at helping the natural process without substituting or replacing it. However, I do not consider such a possibility because there are so few cases to be treated in such a way that this sort of intervention is practically irrelevant and useless.

According to the Roman Catholic Church this principle conforms to (or depends on) 'laws inscribed in the very being of man and of woman'. However, the nature of such laws is not clear: if they were natural laws like that of gravity, for instance, there would be no problem at all, and the situation would be clear and undisputed. If, on the other hand, these laws are supposed to be moral laws, then the controversy begins all over again. As a matter of fact, many people believe that such laws are not indisputably derived from a self-evident principle (nor are they a self-evident principle themselves). In this sense, new reasons should be given to support these 'laws' which allegedly are 'inscribed in the very being of man and of woman'. I cannot see which reasons can be referred to, unless resorting to some quite specific and peculiar metaphysical view of the world. I emphasize this aspect because the inseparability principle is steadfastly affirmed by the magisterium of the Roman Catholic Church, but there are many Catholic believers and theologians who reject it, either intellectually or in practice. Moreover, many other Christian churches are against or do without such a principle. Thus, we cannot say that the alleged inseparable connection between the two meanings of the marital act is really dependent on either revelation or God's will. In this sense, faith as such does not require the inseparability principle, but it may depend on a peculiar metaphysical view of the world. In any case, our question would be whether this metaphysics is acceptable.

It is not my task to enter into such theological or metaphysical disputes, but I do think it is important to remark that for many people the inseparability principle is now merely an obsolete and outdated historical construction having dangerous consequences for societies. In order to reject this principle it is sufficient to remark that it clearly forbids any form of artificial contraception as well as any form of artificial insemination. Therefore, anyone holding that contraception is morally permitted rejects such a principle. On the other hand there are many reasons supporting the morality of contraception. It allows for the control of fertility and is thus beneficial to both the parents and future children who are able to come into life in a more favorable family situation, i.e. when they are desired. In this sense, I think that the inseparability principle cannot claim any serious respectability from a moral point of view, because it impedes potential human fruition. An example is that of homologous artificial insemination, which is also absolutely forbidden by the principle. How can we justify such a prohibition? Why should a couple be prevented from having children (or why should they be forced to adopt)? Is such a heavy burden really justified by the idea that should not separate the alleged two meanings of sexual intercourse? Indeed, I can find no good reason for the inseparability principle and thus have no doubts in rejecting it.

Of course anyone can adhere to it as a guideline for individual conduct, but it can hardly be a valid moral principle for everyone or to be adopted by a society. In any case, since we must realize that there is a situation of conflicting and incommensurable principles, I think that the right solution is to let people behave according to the espoused principle, at least insofar as this does not directly harm anybody else. We must admit that a moral principle is very much like a religious view of the world in the sense that it informs a concept of life and 
the moral agent is totally involved in his/her own moral view. In this sense, since modern societies are founded on religious freedom, we must allow people to live according to their moral views, just as we already allow them to live according to their religions. Therefore, not only is there no reason to force people to adhere to the inseparability principle, but such a solution might be dangerous, since it imposes strong and unjustified limits on personal freedom.

The 'quasi-principled objection' of the equality of all humans beings

Are there other reasons against artificial insemination, once we have abandoned the inseparability principle? If we avoid, as we must, any reference to the inseparability principle, we are left without any other principled objection. There is no other self-evident principle to support the moral wrong of artificial reproduction. However, at this point many authors propose what I refer to as a 'quasi-principled objection', which holds at least for in vitro fertilization. There is a sharp distinction between in vivo and in vitro fertilization, since in the latter a number of embryos are created outside the woman's body, many of which will never be reimplanted in a woman's uterus. Thus, while in vivo artificial fertilization can be criticized only by appealing to the inseparability principle, in vitro fertilization raises more serious moral qualms because of the loss of many early embryos which this practice requires. In this sense, many authors claim that apart from a negative assessment of the practice itself, depending on the inseparability principle in the case of in vitro fertilization it is the means employed to reach the end (the birth of a child) that is morally wrong, because the practice requires the destruction of many early embryos. Since an accepted moral principle affirms the equality of all human beings and early embryos are human beings, the consequence is that it is morally wrong to permit any loss of destruction of human embryos, and therefore many authors contend that in vitro fertilization is morally wrong because the means it requires is morally unacceptable. And it is now clear why this criticism is a 'quasi-principled objection'.

However, the accepted moral principle concerning the equality of all human beings needs to be clarified according to new knowledge deriving from scientific progress in embryology. Considering the fact that in the very first days after fertilization the cells of the early embryo are totipotent, so that this human life process can produce two genetically identical twins, fuse with another process to form a chimera, or become a mole, we realize why the traditional synonymousness is outdated and we have to distinguish carefully between the meanings of the following terms: 'human being', 'human individual', and 'human person'. Until a few decades ago, these terms were synonymous, but we must now realize that there are many situations in which they are no longer equivalent. Clear distinctions must be made. There are human beings that are (still) not individuals: for instance, 'pre-embryos'. And there are human individuals that are not persons (for instance, embryos and human individuals in a persistent vegetative state). Accordingly, I think that the Universal Declaration of Human Rights must be revised, because in such an important document the three terms are considered synonymous. This is because in the late 1940s bioethical problems we deal with today were not on the agenda and discussion of them had not begun. We must thus update our reflection. As for the notion of pre-embryo, see Le Scienze Quaderni no 100, entirely devoted to 'L'embrione ela vita' but in reality discussing the preembryo issue (Mori, 1998b).

In this sense, the above-mentioned principle is to be understood as claiming the equality of all persons. In order to be acceptable, this objection should presuppose that early embryos are already human persons, or at least that there are strong reasons for their being treated as (if they were) human persons. If that is to be accepted, we must admit that any foreseeable destruction of early embryos is equivalent to a sort of genocide, as some authors often contend.

A full discussion of the issues underlying this criticism is beyond the scope of this paper, but once we state the problem clearly enough we must admit that this objection is completely wrong. In fact there are no reasons to hold that early embryos are human persons or should be treated as human persons. On the other hand, there are excellent reasons to say that an adequate interpretation of current biological knowledge leads to the conclusion that they are not persons at all, as I have argued on several occasions (Mori, 1996a, 1996b, 1997, 1998a). I know that my statement may appear too sharp and may be a bit 'dogmatic'. We are so accustomed to hearing that the embryo is a person from the moment of conception onwards that such a sentence sounds 'familiar' and acceptable, even if the only reason to support it is the fact that it is repeated so often. 
Once we try to make sense of it, we must agree with the great Thomist philosopher Jacques Maritain when he wrote in 1971 that "to admit that the human fetus, from the moment of its conception, recei ves the spiritual soul, when the matter is not yet disposed to that operation, is to my mind a philosophical absurdity. It is as absurd as saying that a fertilized egg is already a baby" (Maritain, 1977:98).

I will not further argue my position that the embryo is not a person, because any attempt in this direction would require too long a discussion. I will merely make one further remark showing the absurd consequences of the idea that the embryo is already a person from conception onwards. In order to make this point clear, consider that there is a huge number of fertilized eggs which are lost naturally before birth (some researchers put the figure at about $80 \%)$. That is, for any single birth there are at least four spontaneous early abortions (possibly of embryos which are incompatible with life). This means that if early embryos must be persons, even these embryos would have to be saved (in order to fulfill the equality requirements). We cannot say that we are responsible for such a loss, since it occurs naturally and we cannot be blamed for a natural occurrence. But since we know that fact, if such embryos must be considered persons like us, we should try to avoid their death. Otherwise we would be using them as mere means to our ends. If we do nothing to change the situation, we are part of the greatest 'genocide' performed by nature. We should therefore immediately invest the resources to rescue all naturally aborted early embryos in order to show that we take equality seriously. But apart from the additional burden imposed on normal people if we take such action, we may increase the number of newborns that are al ready unable to live autonomously. Is that what we really want? Do we really think that it is good to modify the order of nature in this direction? I have no definite answer to such questions, but I think that these remarks show how difficult it is to hold the thesis according to which the embryo is a person starting at the moment of conception (Mori, 1998c).

Even while I am firmly convinced that the embryo is not a person, I am ready to admit that we have so far at least two different incommensurable 'paradigms' on the issue (Mori, 1996c). My view is that we can decide which is 'better' and 'more reliable', but I realize that even my opponent thinks the same. We thus have to admit that there are opposing 'paradigms'. But at this point, it is as if we admit that a stand on the issue of the embryo's nature is equivalent to a religious view, and we must thus allow freedom of behavior, for the reasons that I already mentioned above.

If we abandon the idea that any destruction of early embryos is equivalent to murder, then it is difficult to identify any other principled or quasi-principled reason against in vitro fertilization. In fact, assisted reproduction allows for the birth of children who would not be born if such a technique were not available. From the point of view of these children, it is certainly better to be born healthy and in a loving human environment than to never be born at all. By being born they have the chance of a significant life and therefore should be glad to be born by means of an artificial technique. They might suffer some minor psychological problems now, since the practice is still not routine, but such problems appear similar to those experienced by people in special situations, like the first girl in a class of boys or the first people born by cesarean sections (Filippini, 1995). Generally speaking, we can assume that artificial insemination is in the interest of both the newborn (who can only enjoy life by means of such a technique) and the parents (who are able to experience parenthood). In this sense, I see no reason against this new artificial practice.

\section{'Empirical' reasons concerning artificial insemination}

Granted that there are no principled or quasiprincipled reasons against artificial reproduction, I now analyze two 'empirical' reasons which usually are alleged against artificial insemination by donor. One is that the practice breaks the unity of the family. The other is that adoption is a better solution than donor insemination. However, neither gets the point. Upon closer examination, one must realize that the latter is not 'empirical' at all. As a matter of fact, parenthood does not depend on the presence of a biological relation, but on the decision to bring about the birth of a new offspring. From this point of view there is a crucial difference between artificial reproduction and adoption, and the latter institution is relevant to our discussion only because it clearly shows that parenthood does not depend on genetic relationships between the ancestor and the offspring. Being a child is a legal rather than biological relationship (i.e., a social relationship sanctioned by the state).

Besides this point, any other analogy between adoption and artificial procreation is wrong and misleading. The crucial difference 
is that artificial reproduction presupposes a de cision to bring about the birth of a new child, and what is valuable is exactly such a responsible choice. On the other hand, adoption presupposes that someone else decided that a new child had to come into the world, and that this person proved unable to take care of the child that he/ she wanted to come into the world, so that society had to take care of the child in some way. Adoption is one of various ways in which society can cope with the issue. However, the difference between the two practices is now clear, and that cannot be put on the same level. Adoption is always a remedy to an already sad or tragic situation in which those who decided to have the child are unable to care for him/her either because they died suddenly or were unable to do so. In this sense society attempts to find a remedy by assigning the parental role to some responsible people so that the child can receive an adequate upbringing. Therefore, adoption is the least worst solution to a tragic situation, while as an institution it clearly shows that parenthood (or filiation) does not depend on biological relations. On the other hand, artificial insemination hinges on a responsible decision to create a new offspring. In this sense it cannot be compared with adoption. Any limitation to artificial reproduction must be properly justified, and I think there is a serious risk that such reasons may also be applied in the case of 'natural procreation'. If there is no intrinsic reason to respect the 'natural order' as such (since we have already rejected the inseparability principle), then what is important results from certain processes, however they are occur, whether naturally or artificially. If we admit that a given effect brought about artificially is bad or blameworthy, why not pass similar judgment in the case of a similar effect brought about naturally? I therefore think that we should uphold and defend reproductive freedom and let people decide how and when to procreate.

In fact, having abandoned the inseparability principle, I cannot see how we can limit access to assisted reproduction without a similar limitation to 'natural' reproduction. Take the case of a single woman. One could say that it is irresponsible for a woman to have a child and remain single. This could be a reason to deny access to assisted reproduction. Then why is it allowed to provide a single pregnant woman with medical care during pregnancy or childbirth? If it is irresponsible for a single woman to have a child, then the alleged tragic situation of the future child should be sufficient to justify withholding any form of medical care during pregnancy and childbirth. But if we think there is a duty to provide medical care to the woman during pregnancy, why deny care even for conception, i.e., at an earlier stage? I believe these questions show that our prima facieopposition rests only on received opinions from traditions without any valid reason.

The other objection to assisted reproduction is more 'empirical' in the sense that it refers to breakdown of the family, since donor insemination could be a cause of divorce and other pathological family situations. However, such a view is empirically false, since there are data showing that families resorting to assisted reproduction are usually more stable than other couples. There might be other reasons to support such a situation, but it is certain that families relying on assisted reproduction are more stable than other families. In this sense there is no reason to be against such a new practice, and our (possible) opposition is nothing but a cultural artifact that has survived despite any rational justification (Mori, 1995).

\section{Genetic manipulation and its moral implications}

Having argued for the morality of assisted reproduction, I should now say a word about the possible practice of so-called 'genetic manipulation'. This expression appears to be misleading, because 'manipulation' has a negative connotation, alluding implicitly to something wich is supposed to be a priori wrong. However, I take it a as a mere value-free label indicating the newly gained human ability to modify our genetic constitution.

A second preliminary remark is that although they are related, the two issues (artificial reproduction and genetic manipulation) are quite different and independent. The first provides people with a greater possibility of having offspring, while the second provides the option of changing the genetic constitution of our offspring. From a practical point of view, artificial insemination (especially in the in vitro form) seems to be a necessary step to genetic manipulation, but such a goal could be achieved in other ways, for example, by killing any offspring lacking certain features. Of course it might prove quite difficult to accomplish such a program because of social opposition, possibly leading to riots, but such a possibility per se shows that the two issues are independent. It is certainly easier (both socially and technically) to manipulate our genetic constitution if in vitro artificial insemination gives us the possibili- 
ty of examining early embryos, and this is a link between the two issues.

Is genetic manipulation a welcome opportunity for future parents, or is it a nightmare for humankind to come? A major difficulty we encounter in facing this question is that it raises so many problems that it is hard to get to the core of the issue. For example, many people are terrified by the possible disastrous social consequences of some abuse of our new capacity to change our genetic make-up. What would happen if a dictator should gain full control over the new practice? Would it not be a real social disaster for future humankind? These questions are commonplace when we approach the issue of genetic manipulation, but I must say that they are misleading and miss the point. To show that they make little sense, we can ask a similar question. What would happen if a dictator gained full control over all television, radio, newspapers, telephones, etc., so to hold control over all information? Certainly it would be a disaster, but does this possibility show that the invention of television etc. was morally wrong?

I know very well that there are possible abuses of genetic manipulation, as there are for any other practice, but my counter-question shows that we must distinguish clearly between the social problem concerning the political consequences of such a new practice and the moral problem as such. It is this aspect of the issue that I want to consider, and it is crucial that we ask the right question. Once we have abandoned the inseparability principle and realize that there is no intrinsic value in respecting the alleged 'natural order' of human reproduction, the real question is the following: is it morally preferable that the genetic constitution of future offspring be established randomly, or that it be decided by human choice?

This I think is the real question that we have to ask when considering the issue of genetic manipulation. And of course my answer is that human purpose is better than natural chance, because the latter so often causes so much pain. In some cases I am inclined to hold that it would be immoral to let nature take its course and abstain from intervention, because in this way (by not doing, and simply forbearing) we allow some avoidable evil to occur. We can redescribe the situation by saying that if we know (as we possibly do) that some genetic disease affects a new offspring and do nothing to prevent it from occurring, we use nature to harm him/her. In this sense, I think that genetic manipulation is morally permissible and welcome, allowing the possibility of eradicat- ing some terrible human diseases. We can hope that in the future our offspring may enjoy a better biological life, being 'genetically vaccinated' against many diseases. It would be a moral tragedy if we would miss such an opportunity.

I think that most people agree with this view as far as negative genetic intervention is concerned, i.e., that with therapeutic purposes to spare people from disease. But what about the possibility of positive intervention aimed at improving the human race? Is it morally permissible or not? These are difficult questions, but my answer would start by remarking that the distinction between negative and positive interventions in this field is not as clear as we assume at first glance. It is no longer easy to distinguish what counts as a disease (once we have given up the organic concept of it). For instance, is avoidance of Huntington's chorea a negative intervention or a positive one? A person with such a disease can live till about 45 years. Therefore, should we consider an intervention negative because it prevents a disease, or positive because it results in prolonging what is al ready a considerable life-span? The answer may depend on whether dying at about 45 should count as a premature death or not, and this shows how fuzzy (or conventional) the distinction between 'negative' and 'positive' intervention is.

But let us assume that given interventions are definitely positive, like having a more beautiful daughter. Are they morally permissible? And if we allow them, wouldn't it be a social disaster? Shouldn't they be forbidden? Now, first of all we already admit plastic surgery to improve physical beauty. If we had ceteris paribus to achieve the same effect by genetic means instead of by surgery, why should the latter be prohibited while the former permitted? I see no objection to such alleged positive genetic intervention, and I can see no really dangerous consequence of it. The main reason is that beauty is a very subjective notion, and what is beautiful for Tom is not as beautiful for Jerry (and vice versa). For instance, in some parts of Italy a blond, blue-eyed male is considered handsome, while in Scandinavia darkhaired, brown-eyed males enjoy this image. This means that parents would have different choices with an overall improvement in the situation, while everyone would be better off and none worse off or wronged. My view may appear too optimistic, because I assume that parents want the best for their children. Someone may remark that this is not al ways true. I have no answer to such criticism, because it is diffi- 
cult for me to conceive of a wicked parent, i.e., one who would purposely want to harm his/ her child. I generally think of parents who work hard and devote their lives to the good of their children, even if they sometimes make mistakes. In any case, if there are wicked parents, as there may be, they are very few, and we can find ways to prevent them. In general, however, I have the impression that more evil will result if we let nature take its random course rather than accepting the new responsibility of a purposeful choice.

We are at the beginning of a new era, and I think we should not be afraid to face new questions that humankind has to answer.

\section{References}

CONGREGATION FOR THE DOCTRINE OF THE FAITH, 1987. Instruction on Respect for Human Life in Its Origin and on the Dignity of Procreation. Vatican City: Libreria Editrice Vaticana.

FILIPPINI, N. M., 1995. La Nascita Straordinaria. Tra Madree Figlio la Rivoluzione del Taglio Cesareo (Sec. XVIII-XIX). Milano: Franco Angeli Editore.

KASS, L. R., 1997. The wisdom of repugnance. The New Republic, June 2, p. 20.

MARITAIN, J., 1977. Approches Sans Entraves. Scritti di Filosofia Cristiana. Vol. I. Roma: Città Nuova.

MORI, M., 1995. La Fecondazione Artificiale. Una Nuova Forma di Riproduzione Umana. Roma, Bari: Laterza Editore.

MORI, M., 1996a. Is the human embryo a person? No. In: Conceiving the Embryo. Ethics, Law and Practice in Human Embryology (D. Evans, ed.), pp. 151-163, The Hague: Martinus Nijhoff Publishers.
MORI, M., 1996b. II CNB e lo statuto dell'embrione: un'analisi critica del documento e linee di una prospettiva alternativa. Bioetica. Rivista Interdisciplinare, IV:431-460.

MORI, M., 1996c. L'insolubile questione dell'identità dell'embrione. La questione: 'se l'embrione sia o no una persona' è l'equivalente di quella più antica: 'se il sole giri o no attorno alla terra'? Rivista di Teologia Morale, XXVIII:493-499.

MORI, M., 1997. A Moralidadedo Aborto. Brasília: UNB. MORI, M., 1998a. L'embrione. A proposito di un intervento di M. Lombardi Ricci. Rivista di Teologia Morale, XXX:95-98.

MORI, M., 1998b. Presentazione. LeScienze Quaderni, 100:2-4.

MORI, M., 1998c. É razionalmente sostenible la Proposta di modifica delí articolo 1 del Codice Civile? Notiziedi Politeia, XIV (52):32-37. 